\title{
Two Methods For Evaluating Duty To Rescue Proposals
}

\author{
Christopher H. Schroeder*
}

I

\section{INTRODUCTION}

Under American law, a stranger generally bears no duty to rescue another, even another in a life-threatening situation, and even if the rescue could be accomplished with little or no inconvenience or risk. This contrasts with the rule in many European countries that people do bear a legal obligation to render assistance to others in imminent peril when doing so would not place the potential actor at risk. ${ }^{1}$ In his contribution to this symposium, Professor Kleinig examines the support for the American view.

Many who defend the American rule argue that a sharp, categorical distinction separates harm-causing conduct that is properly sanctionable from failures to rescue. Failures to act, including failures to rescue, allegedly exhibit a difference in kind from actions that justify, indeed demand, different legal treatment. That difference is variously described: as the difference between causing harm and conferring a benefit; as that between negative duties and positive duties; as that between duties of a specific obligor to a specific obligee ("perfect" duties) and those that take no specific obligee ("imperfect" duties); or as that between obligations that do not intrude upon individual liberties and those that do. One or more of these distinctions purportedly separates the realm of conduct that the criminal or civil law might properly sanction from the realm that they cannot.

Arguments brought to bear in the debate over sanctioning failures to rescue also include those based on moral, practical, conceptual, and jurisprudential grounds, so that these categorical distinctions are by no means the only points raised in defense of the American position, as Professor Kleinig notes. Indeed, it is so easy to become ensnared in the thicket of debate that has grown up around this question that one risks losing one's way.

Copyright $\odot 1986$ by Law and Contemporary Problems

- Professor of Law, Duke University; Visiting Professor of Law, University of California, Los Angeles, California, 1985-1986.

This paper was prepared for and delivered at the conference on Responsibility, sponsored by Law and Contemporary Problems at Duke University, April 18-19, 1985. It was subsequently revised in light of the discussions at that conference. I am grateful for the comments of John Kleinig, William van Alstyne, and especially for the insightful criticisms of Kate Bartlett, which saved me from several serious errors. Responsibility for remaining errors, serious and otherwise, remain with me, unless they occur during typesetting or printing.

1. See, e.g., Rudzinski, The Duty to Rescue: A Comparative Analysis, in The Good Samaritan and THE LAW 91 (J. M. Ratcliffe ed. 1966). 
Professor Kleinig seeks to slice through this thicket by concentrating on the "deeper sources of our unease" about imposing a duty to rescue that "are most likely to be of interest to philosophers,"2 and he fixes on two issues that exhibit a categorical structure. The first philosophical justification for the American rule he examines rests on the allegedly distinct ontological status of failures to act, such that "failures to act [cannot] . . . be construed as conduct for legal purposes." 3 The second justification, related to the first, is that failures to act, in contrast to acts, cannot "be so related to harms that it is appropriate to contemplate" liability for them. ${ }^{4}$ In his paper, Professor Kleinig argues that neither of these objections is well founded, thus removing two of the most serious arguments against a change in the American rule.

By focusing on fundamental objections, and thus deemphasizing many other issues that are either their derivatives, restatements, or issues of less substance, Professor Kleinig performs a valuable service. As is frequently the case, however, accolades for formulating the significant question do not guarantee agreement on the answer given, and this proposition holds true even between two individuals who agree on the ultimate conclusion, as Professor Kleinig and I do. In this paper I shall argue that the most deepseated objections to a duty to rescue must be located elsewhere than in the two issues Professor Kleinig studies.

By throwing up different objections from those Professor Kleinig identifies, these remarks may appear to join the cause of thwarting change in the American rule. Actually, they are offered in a quite different spirit, one shared, I believe, with Professor Kleinig, namely to assist in the enterprise of intellectually grounding an acceptable duty to rescue. I have not made a complete defense of such a duty here, nor have I described its precise contours. Distilling the fundamental objections to such a duty is, however, a necessary prolegomenon to such an undertaking.

\section{II}

Each of the two objections Professor Kleinig studies claims that a categorical distinction separates failures to act from other conduct, and that this distinction justifies a difference in legal treatment. All such claims invite two distinct types of counterattack. Type I attacks the assertion that a clear boundary exists between the two categories. For instance, it is sometimes claimed that the law ought to enforce only negative duties and not positive duties, that a duty to rescue would constitute a positive duty and that, accordingly, the law cannot impose it. A Type I counter to this claim observes

2. Kleinig, Criminal Liability for Failures to Act, LAW \& ConTEMP. ProBs., Summer 1986, at 161, $162,180$.

3. Id.

4. Id. I have omitted the word "criminal" which appears in Professor Kleinig's text. Nothing in my argument-nor, I believe, anything in his-turns on whether it is criminal or civil liability for failures to act that is being debated, although there is a side debate among those who advocate change from the American rule as to whether only civil, only criminal, or both civil and criminal liability should be imposed. That issue will not be joined here. 
that a negative duty defined as a duty to "refrain from some act which would operate to the prejudice of [another] person" 5 is in fact violated when a would-be rescuer stands idly by (and thus acts by standing) because this conduct works to the prejudice of the victim. ${ }^{6}$

A great deal of energy has been expended defending or attacking various bright line distinctions between acts and failures to act. The central objective of Professor Kleinig's article is to demonstrate that the alleged ontological and causal distinctions are not as sharp and impervious as their adherents have suggested. He claims omissions are specific types of nondoings, typically involving the nondoing of an act that was reasonably expected of the person or that the person had some obligation to perform. Just as the actions of which they are the nonperformance, omissions constitute "acts" not because of their manifestation in any determinate set of physical movements, but rather by their "dashing of certain kinds of expectations." 7 Thus, it is warranted to attribute harm to this species of "act."

With respect to the role failures to act play in causation, we must recall that events are frequently overdetermined, and the law has long attributed responsibility for harm to an event that cannot be shown to be a but-for cause, as when two independently adequate fires converge and destroy a home. ${ }^{8}$ In reciting causal histories, we often look for the unexpected event that will explain why something went awry, why someone was harmed. Insofar as an omission dashes a reasonable expectation, it functions to explain what happened. Because omissions are generally attributable to the specific individuals who possessed the opportunity and ability to perform the omitted act, they and the harm that could have been avoided via the omitted act can be attributed to those specific individuals. ${ }^{9}$

Although I claim no exhaustive knowledge of the philosophical literature on these points (and especially disclaim expertise as an ontologist), Professor Kleinig is obviously responding to spirited arguments in that literature. Notwithstanding the genuineness of these arguments and counterarguments, I believe the entire Type I attack against bright line distinctions misses the mark, because it fails to focus upon the core objections to changing the American legal position.

The Type II response strikes closer to the heart. Type II contests the link between any such distinction and the different legal treatment it is purported to justify. Even assuming that the distinction between positive and negative duties stands up, why does it follow that the law should never sanction the violation of a positive duty? Even assuming that failures to act possess a different ontological status from acts, why should that status be determinative

5. J. Salmond, Jurisprudence 251 (10th ed. 1947). (1983).

6. E.g., Woozley, A Duty to Rescue: Some Thoughts on Criminal Liability, 69 VA. L. Rev. 1273, 1295

7. Kleinig, supra note 2 , at $\mathbf{1 7 3 .}$

8. The classic case is Kingston v. Chicago \& N.W. Ry., 191 Wis. 610, 211 N.W. 913 (1927); see,

e.g., Restatement (SeCond) of Torts \$ 432(2) comment d, illustration 3 (1965).

9. Kleinig, supra note 2 , at 174 . 
of the way the law treats failures to act? These questions start from the assumption that a central reason to sanction failures to act is that doing so can prevent at least some serious harm, including death, from occurring. ${ }^{10}$ Few opponents of a rule change argue against this assumption. It thus seems common ground that one argument in favor of a rule change is that it would be harm preventing. If that is one rationale, then why should the proffering of an alleged categorical distinction, whose categories are not related to harm prevention, be held to be sufficient to resist the promulgation of a harmpreventing rule?

I do not contend that this argument satisfies all objections to a rule change. I contend only that by addressing it can we find the deeper sources of unease concerning any reluctance we may have to sanctioning failures to perform easy rescue. Addressing the argument also dramatically shifts the terms of debate compared to Type I arguments, because whether any particular distinction between acts and failures to act stands up according to the philosophical discipline or subdiscipline that is invoked is now much less important than explaining how different treatment would advance some objective, principle, or policy sufficiently to counterbalance the prima facie appeal of the harm prevention principle. Since harm prevention is tightly connected to a core human interest in survival and physical well-being, the most plausible counterbalances are those that are similarly tightly connected to human interests, values, or principles. These need not be directly harm preventing: The interest in individual liberty frequently invoked in these discussions may relate to the human interest in self-development and selffulfillment, and to the deep human desire to formulate and carry forward individual plans and projects. Still, any categorical distinction faces the same problem of justification that Thomas Scanlon has noted about the idea of rights: "Rights themselves need to be justified somehow, and how other than by appeal to the human interests their recognition promotes and protects?"11

Within Type II, whatever appeal categorical claims have must come ultimately from the invocation of values, interests, or principles to which the categories implicitly make reference. Furthermore, because the valid principle of harm prevention justifies the imposition of a duty to rescue, simply making those references explicit is not enough. It remains to determine whether the gains in the vindication or furtherance of those interests are sufficient to outweigh, offset, or overcome the harm prevention that would otherwise be achieved. Debate over whether failing to rescue

10. Not all arguments for a duty to rescue start from this assumption. Some predicate the legal duty upon a moral obligation to rescue, coupled with the further idea that it is appropriate that (or required that) the law reflect morals. See, e.g., Bohlen, The Moral Duty to Aid Others As the Basis of Tort Liability, 47 U. PA. L. Rev. 219 (1908); D'Amato, The "Bad Samaritan" Paradigm, 70 Nw. L. REV. 798 (1975); Honoré, Law, Morals and Rescue, in The Good Samaritan and the Law 238 (J. M. Ratcliffe ed. 1966). I do not begin here because the link between the duty and harm prevention presents a wider base of common agreement than the moral claim. The conclusion of this paper returns to the connection between moral duty and legal liability.

11. Scanlon, Rights, Goals and Fairness, in Public and Private Morality 93, 93 (S. Hampshire ed. 1978). 
represents a breach of a positive or negative duty, whether it constitutes a harm or a failure to benefit, or whether there is a way of defining liberty so that requiring actions infringes liberty while restraining actions does not threaten to obscure the most basic question of whether the harm prevention obtained by a duty to rescue outweighs the human interests properly underwriting our reluctance to impose that duty.

It is the same, I believe, with the objections on which Professor Kleinig focuses. Whatever the ontological status of omissions, and whether or not a certain kind of causal account pertains to omissions, the ultimate question from a Type II perspective remains the same.

It is just possible that the difference between Professor Kleinig's approach to this problem and my approach reflects the difference between a certain kind of philosophizing and a certain kind of lawyering. To the extent philosophy attends to the chore of conceptual clarity and making precise the way language is or can be employed, debate about the boundaries between ideas and concepts dominate. Lawyers as a breed are certainly not immune from this style of thinking; it was a hallmark of analytical jurisprudence at the beginning of this century in America. ${ }^{12}$ But that brand of jurisprudential thinking has been badly buffeted by the Legal Realists and their descendants, and, although lawyers are still prone to formalistic argument very seldom does it pass careful inspection. Even the most formalistic legal decisions include arguments connecting the formal categories of the opinion to the combination of (conflicting) human interests and values. ${ }^{13}$ The latter form of argument is almost always a matter of more or less, rather than the all or nothing affair to which the categorical claims aspire.

In the following sections I amplify on these remarks and also offer some specific comments on Professor Kleinig's paper. In section III, I suggest that the common law has always been willing to treat (some) failures to act as a sufficient basis for liability without apparent appreciation of the controversy surrounding their ontological status. Because the harm prevention principle provides a basis for imposing sanctions, this legal treatment has been justified. Omissions, whatever their status, play relevant roles in producing or exacerbating harm. In section IV, I argue that the causal relationship between omission and harm is a serious problem for proponents of a change from the American rule, but not because it is inappropriate to designate a failure to act as the cause or even as among the causes of harm.

Some ontologists consider failures to act as a kind of nonevent, a mere negation, an intellectual construct with no characteristic external

12. See, e.g., R. Summers, Instrumentalism and American Legal Theory 136-59 (1982).

13. See, e.g., Paine, Instrumentalism v. Formalism: Dissolving the Dichotomy, 1978 WIs. L. Rev. 997 (arguing that supposedly formalistic judicial decisions cannot be understood without appeal to instrumentalist arguments, and vice versa, and that in fact a sympathetic reading of such decisions shows that both types of arguments are present). 
manifestations. According to this interpretation, failures to act lack the same ontological status as actions. A major burden of parts I and II of Professor Kleinig's paper is to make good the claim that failures to act and "lettings happen" are specific kinds of nondoings, and that as such they possess sufficient "act status" to consider them conduct for legal purposes.

As incisive as Professor Kleinig's discussion is, it is difficult to connect the debate over ontological status with the legal dispute over the propriety of imposing a duty to rescue. If something in that dispute turned on the perplexing ontological status of failures to act, the law would have difficulties not only with respect to the question of a general duty to rescue, but with any rule that holds people accountable for any type of failure to act. Many essays on liability for failure to act $d o$ introduce the problem by claiming that normally one is only held answerable for his actions. ${ }^{14}$ This description makes it sound as if accountability for failure to act is an anomaly, distinguishable from accountability for actions. From here, it is natural to look for something in the nature of failures to act as such, as opposed to actions as such, that explains the difference. However, the presupposition of the legal culture on which this natural progression rests is itself mistaken. The law is replete with rules holding persons accountable for omissions, ranging across administrative law, criminal law, and tort law. ${ }^{15}$ Consequently, a valid objection to the general duty to rescue cannot be founded on the ontological credentials of failures to act as a general class. The issue must be the very different one of why some failures to act ought to be actionable while others, specifically failures to provide easy rescue absent some preexisting relationship, are not.

Tort liability, for example, rests on failures to act far more squarely than commonly realized. A standard formulation of the general cause of action for personal injury requires the plaintiff to prove the defendant "failed to exercise reasonable care." 16 Negligence often, perhaps typically, manifests itself through a failure to act on the part of the defendant. Consider a mechanic hired to fix an automobile. After repairing the master brake cylinder, the mechanic fails to tighten the bolts holding the cylinder to the chassis. As the car comes around a turn, the bolts shake loose, the cylinder falls off, and the car careens over a cliff. It is impossible to describe adequately the causal circumstances leading up to this event without reference, either explicitly or implicitly, to the mechanic's failure to tighten the bolts. If the event is described as above, the reference is explicit; on the other hand, if one merely says, "the mechanic's negligence caused the accident," the failure to act can be brought out by pursuing that with a further

14. E.g., Benditt, Liability for Failure to Rescue, 1 LAw \& PHIL. 391, 391 (1982) ("Usually a person is legally liable, civilly or criminally, for what he has done or caused, not for what he has failed to do or allowed to happen.").

15. See infra notes 20-21 and accompanying text.

16. E.g., D. Dobbs, Torts and Compensation 97 (1985). 
question: "Just how was it that the mechanic was negligent?" Failure to tighten the bolts will emerge from beneath the surface.

This example highlights the standard distinction between malfeasance and nonfeasance. The current point of the example, however, bears on the matter of the ontological status of failures to act and the relevance of that status to the question of a general duty to rescue. Suppose that there were a connection between these two issues, so that only events of a certain ontological status were adequate for purposes of legal accountability, specifically for liability on the basis of negligence. Actions possess the requisite ontological status. Suppose further, as some of the writers whom Professor Kleinig criticizes apparently believe, that failures to act cannot be ontologically assimilated to actions. Then there is no action in the mechanic's example of the sort that satisfies the other conditions of legal liability (let us assume that up to the point of failing to tighten the bolts the mechanic had performed every act of master brake cylinder repair with impeccable skill). We have a case of non-negligent repair up to the point of bolt tightening, followed by a failure to tighten the bolts. The actions of non-negligent repair cannot supply a basis of liability, because they are non-negligent; the failure to tighten bolts cannot because it lacks the requisite conduct status.

Such cases, if the account of ontological status being connected to the legal issue were correct, should be very troubling. It might well be that we could work out some exceptional justification for them, but some special justification for them would seem required if our governing principle were that some event sharing the ontological status of actions had to form the basis for a rule of accountability. Quite to the contrary, the example just described is considered a garden variety example of negligence, comparable to a case in which an overzealous mechanic winds the bolts too tight, sheering off their threads so that they release, which in turn causes the cylinder to break off, and the car to go over the cliff. Both are standard examples of negligence.

The mechanic's example manifests misfeasance, as distinguished from nonfeasance, and on one traditional account liability for misfeasance is not predicated on failure to act. ${ }^{17}$ According to this view, the mechanic has entered into a course of dealing, or an "undertaking"-namely the performance of master brake cylinder repair-that he can be required to perform according to the normal standard of care. He would not have been accountable for not undertaking to repair the brake cylinder, even if he had come across you on a mountain road and comprehended that the car was the only way to get your wife down the hill for an operation necessary to save her life, but once having undertaken to repair the car, he is responsible for negligent performance of that undertaking. Some analysts have deployed this description in a self-conscious effort to avoid placing liability on the failure to act, a basis for liability with which they have seemed quite uncomfortable. Perhaps their efforts to articulate explanations that do not involve liability for

17. On the distinction, see generally W. Prosser \& P. Keeton, Prosser and Keeton on the LAW OF TORTS $\$ 56$ (5th ed. 1984). 
a failure to act have stimulated the view that failures to act are suspect bases for legal accountability. Holmes, for instance, claimed that although the "immediate occasion of the damage ... may have been a mere omission ... if you connect it . . . with the previous dealings, you have a course of action and conduct which, taken as a whole, has caused or occasioned the harm."18 The trick is to see that the defendant's entire behavior "consisted of a combination of acts and neglects, which taken as a whole amounted to an improper dealing with the thing."'19

This account reflects considerable ambivalence on Holmes' part with respect to failures to act as a basis for liability, but it does not provide a satisfactory explanation of how to overcome it. Recourse to the idea of an undertaking or the defendant's dealing leaves unexplained why that should provide a basis for liability when the only improper aspect of the dealing was a failure to act. It is more straightforward to describe an undertaking as a complex activity by the defendant within which he will be held responsible for certain failures to act as well as certain affirmative actions. In cases such as the mechanic's failure to tighten the bolts, the failure to act remains the specific event for which he is held responsible, for if he had not failed to tighten the bolts we would not have held him accountable. While we must still determine why certain complexes of human interactions involve undertakings within which failures to act are actionable, nothing in such a search entails believing that failures to act within such undertakings must be ontologically distinguishable from those outside them. ${ }^{20}$

Other legal requirements operate on failures to act. The Administrative Procedure Act provides that a failure to act by an agency is judicially reviewable. ${ }^{21}$ The Model Penal Code defines conduct as "a voluntary act or the omission to perform an act of which [one] is physically capable," and then

18. O. Holmes, The Common Law 279 (1881 \& reprint 1949).

19. Id. at 280 .

20. At least one other explanation for liability has been propounded that might rehabilitate the significance of the asserted ontological distinction. Under it, liability in a case like the first mechanic's failure to tighten the bolts arises solely because the previous actions of the mechanic had created a dangerous situation that contained all the ingredients necessary to injure the plaintiff. Only in cases where an actor's subsequent inaction allows the completion of the actor's causation of injury can we say that the actor is responsible. Only in such cases does a positive duty exist for the actor to prevent that harm from occurring, and that positive duty is entirely attributable to the actor's having created the dangerous set up through his actions. E.g., Epstein, A Theory of Strict Liability, $2 \mathrm{~J}$. Legal Stud. 151, 160, 192 (1973); Mack, Bad Samaritanism and the Causation of Harm, 9 Phil. \& Pub. AfF. 230, 240-41 (1980). One might therefore assert that the previous actions of the actor supply the requisite ontological status to the situation; the failure to act merely completes a description of how the injury ultimately occurred. This avenue does not prove successful, however. For one thing, it could succeed only if strict liability, rather than negligence, were the standard of liability, for in cases like the mechanic's failure to tighten, we have no actions that possess the requisite ontological status and also fall below the standard of care of negligence. Second, it does not seem to account for all cases even under a strict liability approach. Suppose that the mechanic in our hypothetical were not the first, but the second, to work on the car. The first had splendidly performed all the actions of master cylinder repair up to the point of bolt tightening, but then left the job for some legitimate reason (had a heart attack, perhaps). The second comes in to finish, observes the untightened bolts, but does nothing. The second will be held liable for the subsequent accident even though he has performed no actions that caused the injuries. He will be held liable for failing to act.

21. 5 U.S.C. $\$ \$ 51(13), 701-02$ (1985). 
defines many criminal offenses in terms of "conduct."22 Innumerable specific statutes render individuals accountable for failures to act, from failure to file a tax return on April $15^{23}$ to failure to report spilling oil into the navigable waters of the United States. ${ }^{24}$ The legal landscape is heavy with provisions that hold people responsible for failures to act. To the extent that a general duty to rescue has not yet been included in that landscape, it seems more plausible to conclude that something about the nature of that particular failure to act or letting happen causes trouble, not that failures to act as a class present some ontological conundrum.

In sum, I do not disagree with Professor Kleinig's conclusion that ontological considerations ought not to bar ascribing legal responsibility for failures to act. Consideration of the common law's treatment of tort doctrine suggests that no ontological bright line has stood in the way of liability for failures to act. The search for the deep obstacles to such liability must turn elsewhere.

IV

In legal contexts, causal connections operate to join certain end-states, usually harms that have been suffered by individuals, to prior conduct. Such connections are typically dissected into two components: but-for causation and proximate causation. That simple division, however, does not capture the idea of legal cause in all its guises. It is insufficient, for example, when events are overdetermined, as when forest fires converge. In such cases, we might find a negligently set fire to be causally connected to the harm caused by the combined fires, even though it was not a but-for cause of that harm. However, it fits many cases well and, just as important, it accords well with people's firstlevel conclusions about what is meant when causal responsibility is assigned.

One point of section IV of Professor Kleinig's paper is that failures to act can be causally connected to harms for legal purposes because they satisfy both a modified but-for causal condition and a proximate causation condition. A failure to rescue satisfies the but-for condition once the relevant end-state is identified not as "harm to $\mathrm{X}$," but rather as "harm to $\mathrm{X}$ under circumstances in which $\mathrm{Y}$ could have prevented the harm by action $a$." Modifying the endstate description is acceptable because, by definition, "failure to act" means there was a reasonable expectation that $\mathrm{Y}$ would perform action $a . .^{25}$ Thus, in the mechanic's example, we include failure to tighten the bolts in our causal account because we expect the mechanic normally will tighten them. Although the second half of the argument is not as clearly spelled out, presumably the proximate causation condition is met because it is fair to blame $\mathrm{Y}$ for exacerbating $\mathrm{X}$ 's condition or allowing it to continue to

22. Model Penal Code $\$ 2.01$ (1) (Official Draft, 1962).

23. 26 U.S.C. $\$ 6072$ (a) (1982).

24. 33 U.S.C. $\$ 1321(\mathrm{~b})$-(j) (1982).

25. See Kleinig, supra note 2, at 169. 
deteriorate (his failure to act is not "innocuous" 26 when he could act without risk or expense to himself).

This account helps explain why we commonly consider it a moral responsibility to perform acts of rescue, and opens the way to argue that legal responsibility, commonly thought to require a causal connection, is also appropriate. Again, however, Kleinig's position constitutes a Type I attack on the categorical claim that failures to act cannot be cited as causes of harm. ${ }^{27}$ Once attention turns to Type II issues, this debate becomes largely irrelevant. ${ }^{28}$ On the one hand, if failures to act can be causes, the issue of assigning legal responsibility for these causes is not yet resolved. On the other hand, even if failures cannot be called causes, the actions they are omissions of can still be harm preventing, and thus prima facie candidates for legal sanctions on that ground. The assumption that drives the causal objection to a duty to rescue-that only acts that are causes of harm should be sanctioned-must be defended by linking that claim to underlying interests, values, or principles.

In fact, a Type II argument can be made against a duty to rescue based on the role that failures to act play in causal accounts of harm, one that does not depend on the issue Professor Kleinig has joined. Even assuming failures can be causes, failures to act have a different causal logic than actions, and this difference creates, for the proposal to sanction failures to rescue, certain difficulties relating to our interest in individual liberty.

It is clear that unadorned but-for causal accounts capture many more actions than we are prepared to consider legally responsible for harms. Every action causes ripples forward in time, and often it is possible to say that but for a much earlier ripple generating event a harm would not have occurred. One torts casebook uses an apocryphal but illustrative case to make the point. ${ }^{29}$ In the illustration, the plaintiff's garage burned down at the hands of six-year-old William. The plaintiff sued a surgeon who before William's birth had performed an operation on William's father, at the father's request, to render him sterile. Without the surgeon's negligence, William would never have been sired, and this particular fire would not have occurred. The court was unwilling to hold this but-for cause legally responsible for the plaintiff's loss. ${ }^{30}$ In a case like this, the doctrine of proximate cause operates to cut off legal responsibility.

In a moment, I shall argue that some of the notions of proximate cause operate differently in the case of inactions than in the case of actions. Before this, however, we should notice a difference in the but-for aspect of legal

26. Id. at 170 .

27. Just such a claim has been strenuously argued in Mack, Bad Samaritanism and the Causation of Harm, 9 Phil. \& Pub. Aff. 230 (1980).

28. See, e.g., J. Feinberg, Harm to Others $171-72$ (1984) (arguing that if the distinction between causing harm and allowing harm to happen lacks moral significance, the contention that failures cannot be causes is moot).

29. D. Dobbs, Torts and Compensation 197 (1985).

30. Id. 
cause as it applies to failures to act. While actions send ripples into the future, many of those ripples join, and eventually are overborne by others to an extent that the effect of the earlier ones is obliterated. We are then no longer willing to ascribe causal status to the earlier events. The clearest instance of this principle may be the idea of novus actus interveniens, meaning that the action of another agent, itself not causally determined by the earlier action, has intervened and superseded the earlier action. Suppose, for example, that a teenage William burned down the garage. We would be unwilling to hold William's father responsible on the ground that he had treated William harshly as a youth, in part because the theory linking parental abuse and specific acts of subsequent juvenile delinquency, although suggestive, is too weak. We believe the influence of the parent has been overshadowed by the ability of William to make his own choices. In such cases, we doubt whether the defendant's action was a but-for cause of the plaintiff's harm.

Failures to act are not superseded in the same way. When we fail to respond to a plea for aid to sub-Saharan Africa, the role of that failure is not so obviously intersected by other subsequent events, because we continue to fail to respond so long as there remains opportunity to do so. ${ }^{31}$ Many people may be similarly failing to act, but those additional failures do not overwhelm the ripples of our failure in the way that subsequent actions overcome the causal responsibilities of our actions. Nor is there the same kind of spatial bounding of failures to act as pertains to most actions. Whereas the ripples of many actions are limited by physical laws, we can fail to act across vast distances, even to the other side of the world. Many of those actions that do have potentially broad spatial reach, furthermore, are ones we can choose to engage in or not. The mechanic will be responsible for your injuries even if you take the car to Alaska and have the accident there, but he knows at the time he begins repairing your car that this is the kind of instrumentality he is dealing with.

When but-for causation has been made out, the doctrine of proximate cause implements some of our frequently vague judgments as to when individuals should nevertheless not be liable for harm to others. These judgments probably cannot be reduced to a single principle, but some of the constituents of proximate cause function much more clearly to shield us from responsibility for our actions than they would from responsibility for our inactions. For instance, part of the justification for the novus actus doctrine arises not from mechanistic causal theories, but rather from notions of individual responsibility. Any action will be partially the product of the circumstances that confront the agent, and an agent's response to those circumstances will be partially determined by how that person has been influenced by others during his development. Nevertheless, we often refuse to associate earlier actions that created those circumstances or influenced that

31. If one wishes to place a temporal dimension on failures to act, then one would not say that the failure continues, but rather that one is capable of repeating the failure, and does so an indefinite number of times, in that way renewing its role in the causal story. 
development with a future harm because we hold the agent who acts nearer in time to the harmful occurrence responsible for anticipating adverse consequences and having the will to avoid them. There is often a proximate cause element in the novus actus doctrine as well as a but-for element. We refuse to hold William's father liable, even though we believe early harsh treatment creates propensities for delinquent acts, because we wish to hold William primarily accountable.

This kind of proximate cause principle is not as readily available to cut off responsiblity for failures to act as it is for actions. Because we can continue to fail to act indefinitely (or renew our failure an indefinite number of times), those failures remain proximate to the harm. They therefore have less the characteristic of causing ripples into the future than they do of constantly agitating the waters. Many other people may also be failing to act, but their failures do not seem to intervene to save us from responsibility for ours-we are all failing to act equally.

The relative lack of causal cut-offs between failures to act and harms, as compared with those available in our normal understanding of actions, places tremendous pressure on the concept of "reasonable expectations" within the definition of failures to act, because that limiting concept may be about all that will stand between us and legal responsibility for many, many harms that we could have prevented. The usual hypotheticals enter in here to press our intuitions about whether that line can be held. As Richard Epstein questions, if a strong swimmer is legally liable for failure to make an easy rescue of a drowning infant in a swimming pool, will you be similarly liable for failure to donate $\$ 10$ to African relief if you are substantially certain that that $\$ 10$ will prevent a death through starvation ? $^{32}$ Similarly, as a note pinned recently to a bulletin board at Duke University Law School queried, if you make $\$ 45,000$ per year as an entry level associate at a corporate law firm and can live securely on $\$ 20,000$, are you legally answerable for the deaths of one hundred Africans, on the assumption that $\$ 250$ per year would sustain a life indefinitely? Or, as someone asked in a penned response to the original note, if you go to work for legal services at $\$ 20,000$ a year, but could have taken a job with a corporate law firm and then donated your surplus $\$ 25,000$ to relief organizations, are you still culpable?

These hypotheticals, and variations on them, are familiar. If some line cannot be drawn separating legally sanctioned failures to act and morally blameworthy but legally permissible ones, extending liability for failures to act threatens to make legally impermissible all those things we do when we are failing to do the many good things we might do. This line drawing is important, because if proposed rules of legal liability create standards that individuals can meet only through burdensome measures, in terms of beneficial actions foregone in order to avoid liability, those rules impose a cost on individual freedom that should count in an analysis of whether such

32. Epstein, $A$ Theory of Strict Liability, 2 J. LeGal STud. 151, 198-99 (1973). 
liability should be imposed. It is through this accumulation of actionsactions the duty to rescue threatens to prohibit or penalize-that the claim that such a duty violates our individual liberties has bite. Thus, Richard Epstein suggests:

[O]nce one decides that as a matter of statutory or common law duty, an individual is required under some circumstances to act at his own cost for the exclusive benefit of another, then it is very hard to set out in a principled manner the limits of social interference with individual liberty. ${ }^{33}$

This argument must be distinguished from the quite different notion sometimes advanced that requiring a positive action, as such, is more invasive of liberty than forbidding an action. On an individual basis, this proposition has little merit. Often it is possible to pair up actions and omissions that seem indistinguishable in terms of their impositions on liberty. "Is it more of a deprivation of liberty to be told you have to call the police if you see a person in danger than to be told you cannot turn right against a red traffic light?" 34 Rather, it is when the cumulative effects of all the failures for which we are accountable are added up that liberty is significantly implicated. Liability for failures, as such, may be somewhat more invasive of liberty than liability for actions, just because situations in which we can fail to act can be thrust upon us, and hence our ability to control our affairs is lessened. ${ }^{35}$ It is only as the range of such situations and the frequency with which they will be thrust upon us increase, however, that the duty to rescue seriously implicates a concern over freedom of action.

Nor does this argument invoke what A.D. Woozley has recently termed that venerable "flesh-creeper, The Principle of the Wedge." 36 The Wedge argues against right action in the immediate case on the ground that doing the correct thing now will make it impossible to avoid the correct thing in future cases, when we no longer want to do it. ${ }^{37}$ Here, the problem is that the cumulative effect of a series of individually right decisions (insofar as the controlling principles defining a duty to rescue are concerned) may result in constraining too much freedom of action. To prevent that accumulation, some limiting principles must be implemented. The difficulty is that many of the recognized limitations on liability available in cases of alleged liability for actions will be unavailing when dealing with failures.

This difficulty cannot be derided as merely a problem in legislative draftsmanship. ${ }^{38}$ First, the argument in favor of a duty to rescue often aims to provide a reason for judicial decision under common law principles, where the demands for a principled line are greater. Judicial judgments seek expression in terms of general considerations rather than arbitrary divisions. Legislatures draft arbitrarily precise lines in enacting statutes of limitations,

33. Id. at 198 .

34. T. Gray, The Legal Enforcement of Morality 163 (1983).

35. See J. FeinberG, supra note 28 , at 164.

36. Woozley, supra note 6 , at 1299.

37. F. Cornford, Microcosmographia ACademica 15 (1908).

38. See, e.g., Woozley, supra note 6, at 1299. 
for example, while courts acting on their own employ the equitable principle of laches, or unreasonable delay under the circumstances, to bar stale claims from litigation. Second, while it may be true that a firm, albeit somewhat arbitrary, line delimiting rescues to which a legal duty attaches would be superior to a legal regime wholly without such a duty (and certainly my contention that Type II considerations ought to control this issue is consistent with that proposition), it is nevertheless important to isolate those criteria that influence where that line ought to be drawn. These criteria serve at the least as counsel to a conscientious legislator, and also clarify what we actually believe separates the case involving the drowning child and the strong swimmer from the ten dollar charitable contribution. What functions, in other words, to make certain expectations about rescue reasonable to a degree that warrants legal sanction for a failure to rescue?

If this last question could be answered satisfactorily, perhaps a case for judicial action, as opposed to legislation, could indeed be made. Historically, we have left the judgment of what constitutes reasonable care in cases of putatively negligent actions to a jury subject only to general guidance from the judge. Analogously, Joel Feinberg, among others, has recently argued that the relevant general considerations for failures to act can be articulated in the same manner, thus making judicial imposition of the duty possible. ${ }^{39}$ I shall not review that argument exhaustively here. In the context of the present discussion, its interesting feature is that the principles suggested to cabin the duty to rescue respond directly to the concern that an unconfined duty severely curtails individual liberty, perhaps sufficiently to overbear the harmprevention gains from recognizing it.

Some of those principles appear in the Vermont statute requiring easy rescue, which is often cited as a model. It reads:

A person who knows that another is exposed to grave physical harm shall, to the extent that the same can be rendered without danger or peril to himself or without interference with important duties owed to others, give reasonable assistance to the exposed person unless that assistance or care is being provided by others. ${ }^{40}$

Frequently, the "easy" aspect of this duty is emphasized: "without danger or peril to himself." The difficulty examined here, however, demonstrates the critical importance of a second kind of limitation, namely the limitation on the kind of dangers to which people must respond. Arguing for a duty of easy rescue, Feinberg goes even further in restricting the scope of the duty by employing the metaphor of "love thy neighbor." "When it comes to aiding the imperiled, all people who happen to find themselves in a position to help-all who have by chance wandered into the vicinity, or 'portable neighborhood,' of the imperiled party - are his 'neighbors.' "'41 The neighborhood of the victim constrains the duty spatially, while the immediacy that is implicit in the idea of

39. J. FeINBERG, supra note 28 , at 130-40.

40. VT. Stat. AnN. tit. 12, §519(a) (1973).

41. J. Feinberg, supra note 28, at 133. 
peril does so temporally. ${ }^{42}$ The more tightly one defines peril in terms of the certainty of immediate harm, and the more tightly one draws the victim's portable neighborhood around him, the fewer people will be subject to any duty to rescue. If one must be hanging by a finger from a sheer cliff with exhaustion just seconds away, few people will ever receive knowledge of the peril, and fewer still will be able to do anything about it. Only the neighborhood feature distinguishes the drowning infant from the starving in Africa, for surely supplying aid to Africans is as little fraught with danger or inconvenience for many of us as is jumping into the pool. If, however, death must be seconds away before a neighborhood forms around an individual, then few in the United States will ever be in the neighborhood of particular Africans.

The inapplicability of causal cut-offs normally available in cases of alleged liability for actions was earlier cited as a cause of the concern that the duty to rescue would encompass too much of an individual's life to be acceptable. Feinberg's neighborhood concept can be interpreted as a response to that concern. The neighborhood concept performs a role in causal stories containing failures to act analogous to that of novus actus interveniens in causal stories containing actions; it shifts legal responsibility away from a temporally or spatially distant actor (comparable to William's father) to one closer in time and place, so that the near individual functions as an intervening agent.

To limit the inroads on freedom of action to acceptable levels, the confines of the portable neighborhood must prove durable. They must contend with the tendency of courts to respond to and to expand such principles over time. Thus, before the complete case for a duty to rescue can be proposed, we do well to conjecture briefly as to whether the neighborhood concept will actually constrain the duty to an acceptable universe, or whether the boundaries of that universe will be placed under expansionary pressure once the judiciary recognizes it.

Developments in two related areas of law suggest caution. First, courts have principles that help determine whether to grant injunctions against potentially harmful behavior. These principles apply to cases that might be characterized as anticipatory rescue: When do individuals have to forbear from actions that might produce harm? The traditional rule in the equity courts resembled the closely confined terms of the neighborhood proposal. Injunctions were appropriate only in situations where the plaintiff could demonstrate the substantial certainty of imminent irreparable harm. Over time, driven largely by the changing nature of risks associated with modern technology and by the increasing apprehension of the risks associated with the environmental era, courts have determined that the necessary degree of probability that the harm will occur varies inversely with the harm to be

42. "Exposed" to harm, the language of the Vermont statute, does not so clearly carry an implication of immediacy, and is perhaps vulnerable on that ground. See VT. Stat. AnN. tit. 12 , $\S 519(\mathrm{a})(1973)$. 
avoided-the greater the harm, the smaller the possibility required. ${ }^{43}$ Were the duty to rescue principle to follow a similar progression, one should anticipate that the size of the portable neighborhood would expand with the size of the catastrophe, perhaps even far enough to bring the African famine within its purview.

The second area of related development concerns the duties to prevent harm caused by third parties imposed on defendants who are held to be in a preexisting relationship with the plaintiff. The preexisting relationship rule provides an exception to the American rule of no duty to rescue. The variety of relationships held to fall within the exception has expanded considerably in recent years, as have the obligations imposed by a preexisting relationship. ${ }^{44}$ One aspect of that responsibility is to prevent harm caused by third parties. Thus, hospitals, hotels, airports, commercial establishments, landlords, and homeowners bear a duty "to take affirmative action to control the wrongful acts of third persons which threaten invitees where the [owner] has reasonable cause to anticipate such acts and the probability of injury resulting therefrom." 45

In landowner cases, the boundaries of the defendant's property limit the physical neighborhood an invitee must enter before an obligation is triggered. The scope of that duty, however, can extend considerably beyond easy measures. As the Supreme Court of California sees it, the duty varies with a number of factors, including the foreseeability of harm, its probability, the "closeness of the connection between defendant's conduct and the harm," defendant's moral blameworthiness, and the extent of the burden on the defendant from requiring preventative action. ${ }^{46}$ As the likelihood and severity of danger increase, the California court is prepared to require quite extensive and risky precautions of defendants, as it did recently in Isaacs $v$. Huntington Memorial Hospital in finding that the failure of the hospital to supply armed guards for hospital parking lots could support a jury conclusion that the hospital had breached its duty to its invitees. ${ }^{47}$ Placing employees, such as the guards, at risk in order to rescue invitees takes responsibility to act affirmatively well beyond the scope suggested by most easy rescue proposals. In fact, the scope of duty in the landowner cases appears to have become nearly identical to that in ordinary negligence actions: the defendant must engage in preventative or rescue activities that are "reasonable under the

43. The history of this change is summarized in Schroeder, Rights Against Risk, 86 Colum. L. Rev. 495 (1986).

44. So much growth has occurred, that this may partially explain the lack of any concerted and successful movement to modify the American rule by statute. Many of the compelling cases for the duty may be reached by determining that the defendant and the plaintiff had a preexisting relationship.

45. Isaacs v. Huntington Memorial Hosp., 38 Cal. 3d 112, 123, 695 P.2d 653, 657, 211 Cal. Rptr. 356, 360 (1985) (quoting Taylor v. Centennial Bowl, Inc., 65 Cal. 2d 114, 121, 416 P.2d 793, 797, 52 Cal. Rptr. 561, 565 (1966)).

46. Id. at 124-25, 695 P.2d at 658, 211 Cal. Rptr. at 361 . Other relevant factors include the public policy favoring compensation of injured parties and the cost and availability of insurance.

47. Id. at 129, 695 P.2d at 663,211 Cal. Rptr. at 366. 
circumstances,"48 implying that quite expensive precautions and actions might be required in appropriate cases where probability of harm combined with its severity are high.

The preexisting relationship cases could well be relied upon in subsequent interpretations of a general duty to rescue. The absence of a fixed location for which one is responsible may bear on the scope of that general duty, but "reasonable under the circumstances" supplies a capacious umbrella to permit general submission to the jury, a body which may be less influenced by the cumulative effects of expansive liability findings than by the more tangible claims of the immediate parties.

If these trends in the law of injunctions and preexisting relationships are any guide, the idea that carefully drawn general considerations could confine the requirement of a general duty to rescue to a relatively small class of failures to act is open to question. Certainly this possibility does not end the case for a general duty to rescue. It may be that the suggestions from these other areas are false clues, and that one can sketch a rationale for easy rescue that would provide a discriminating basis to separate legally sanctionable failures from morally blameworthy but legally innocent failures. Conversely, some might respond to the parade of African relief hypotheticals by claiming that they, too, should fall within a legal duty, although the objection to this conclusion from the principle of individual liberty seems to me formidable.

\section{Conclusion}

In fact, despite the objections I have raised, I believe some duty to rescue might well be imposed without undue interference with liberty interests. It has not, however, been my ambition to trace the case for a duty to rescue comprehensively, but rather to speak against a certain way of approaching the issue and in favor of another way. The question eventually must be settled on the kind of arguments advanced here, arguments that inevitably turn on considerations of whether "undue" costs to human interests or principles would result from establishing such a duty. The prima facie appeal of that duty is legitimate, and none of the categorical claims against it successfully responds to that appeal.

Professor Kleinig concludes his paper by maintaining that, despite all the commentary on the problem we have been analyzing, we have not sufficiently illuminated the reasonableness of the moral duty to render easy aid. Further candor and argument on the moral issue are needed in order to clarify the case for a legal duty to rescue. The merit in that suggestion is substantial and bears reinforcing. Some forms of moral discourse share the Type I structure I have argued against here in the context of legal theory. Pursuit of these forms will lead debate down the same tortured and blind alleys as those which the legal dispute has largely followed. The contours of the moral issue do need

48. Id. at 131, 695 P.2d at 663, 211 Cal. Rptr. at 366. 
exploration along avenues that avoid that danger, for I suspect, as Professor Kleinig apparently does also, that beneath a surface of consensus that there is such a moral duty lies a deep and substantial disagreement about how encompassing that duty is.

The moral issue cannot be ignored, finally, in addressing the legal question. Common law principles are intertwined with moral principles in ways more complicated than we understand. While legal principles do not simply reflect specific moral systems or even the morality of the common culture, neither can those legal principles become too dissociated from their moral analogues without the erosion of their authoritativeness. The entire prior discussion of the inapplicability of traditional causal cut offs to the realm of failures to act and the subsequent wariness with which one might view judicial interpretation and application of some general duty to rescue could be rephrased as a problem in the dissociation of law from its kindred morality. Decisions such as Isaacs are open to criticism because those decisions and their animating rationales seem to have become unmoored from the moral base to which we used to think them anchored. My colleague, William Van Alstyne, suggests that California tort decisions seem to be pursuing the principle of "proximate solvency," under which a financially capable party will be held liable almost solely on the basis of having been on the scene, if that is necessary to ensure a solvent source of recovery for the plaintiff. Considerations of loss spreading and ensuring compensation can be marshalled in support of the proximate solvency principle, but those considerations are a far cry from the principles of moral responsibility that underlie older notions of corrective justice long thought to motivate the development of tort law.

If a persuasive case can be made that a general duty to rescue in the hands of a court following the proximate solvency principle would likely be converted into individual decisions extending entirely too far into the competitive realm of freedom of action, it is because some substantive criteria that define what is "too far" are giving the case its persuasive force. Many of those criteria come from kindred moral principles. I believe we will find that the relevant moral issues can be fleshed out only through the Type II structure I have argued for, and I suspect it will be no easy task. There are, after all, moral arguments for outcomes such as Isaacs. However, I can agreeably end this comment on Professor Kleinig's excellent paper by seconding his insight that the moral debate holds the key to illuminating the controversy over a legally enforceable duty to rescue. 